\title{
Gene expression following induction of regeneration in Drosophila wing imaginal discs. Expression profile of regenerating wing discs
}

\author{
Enrique Blanco ${ }^{3}$, Marina Ruiz-Romero ${ }^{3}$, Sergi Beltran ${ }^{1,3}$, Manel Bosch ${ }^{1,3}$, Adrià Punset $^{2,3}$, Florenci Serras ${ }^{3}$, \\ Montserrat Corominas ${ }^{3^{*}}$
}

\begin{abstract}
Background: Regeneration is the ability of an organism to rebuild a body part that has been damaged or amputated, and can be studied at the molecular level using model organisms. Drosophila imaginal discs, which are the larval primordia of adult cuticular structures, are capable of undergoing regenerative growth after transplantation and in vivo culture into the adult abdomen.

Results: Using expression profile analyses, we studied the regenerative behaviour of wing discs at 0, 24 and 72 hours after fragmentation and implantation into adult females. Based on expression level, we generated a catalogue of genes with putative role in wing disc regeneration, identifying four classes: 1) genes with differential expression within the first 24 hours; 2) genes with differential expression between 24 and 72 hours; 3) genes that changed significantly in expression levels between the two time periods; 4) genes with a sustained increase or decrease in their expression levels throughout regeneration. Among these genes, we identified members of the JNK and Notch signalling pathways and chromatin regulators. Through computational analysis, we recognized putative binding sites for transcription factors downstream of these pathways that are conserved in multiple Drosophilids, indicating a potential relationship between members of the different gene classes. Experimental data from genetic mutants provide evidence of a requirement of selected genes in wing disc regeneration.
\end{abstract}

Conclusions: We have been able to distinguish various classes of genes involved in early and late steps of the regeneration process. Our data suggests the integration of signalling pathways in the promoters of regulated genes.

\section{Background}

The process of regeneration allows organisms to recreate the original shape, size and function of body parts that have been lost or damaged. Regenerative capacity varies between species, ranging from simple wound healing to unrestricted regeneration of all body parts $[1,2]$. Since the basis of regeneration was first established by T. H. Morgan [3], an extensive body of literature has been published describing the different mechanisms of regeneration employed in many different species. For instance, regeneration of complete individuals from any tiny body fragment has been studied in

\footnotetext{
*Correspondence: mcorominas@ub.edu

${ }^{3}$ Departament de Genètica, and Institut de Biomedicina de la Universitat de Barcelona (IBUB), Diagonal 645, 08028 Barcelona, Catalonia, Spain Full list of author information is available at the end of the article
}

freshwater planarians and hydra $[4,5]$, and limb regeneration after amputation has been explored in detail in amphibians and teleost fish [6-8]. Regeneration of heart, liver, pancreas, and other organs has been also extensively studied in zebrafish, mouse and human [9-12].

Drosophila imaginal discs, the larval primordia of adult cuticular structures, are capable of undergoing regenerative growth. When imaginal discs are manually fragmented and cultured in the abdomen of adult flies, cells at the wound site undergo proliferation and regenerate the missing part. Pioneering experiments demonstrated that regeneration induces limited cell plasticity, enabling the reconstitution of missing tissue while disc identity is maintained (reviewed in $[13,14]$ ). In rare cases, however, the initial fate was lost in some subsets of proliferating cells, which acquired the identity of 
another disc type in a phenomenon named transdetermination $[15,16]$. As in many other systems, regeneration of imaginal discs involves wound healing and blastema formation $[17,18]$. In a rapid response to injury, epithelial and cytoskeletal changes occur during the first 24 hours. Concomitantly, local proliferation increases and peaks around 2-3 days after fragmentation $[19,20]$. This in vivo culture system has proven to be a powerful method for studying the regenerative process at the tissue and cellular level, and what is known about the underlying molecular mechanisms implicates several signalling pathways.

The JNK signal transduction cascade is activated by exposure of cells to cytokines or environmental stress. Multiple studies have demonstrated that JNK regulates cell proliferation, apoptosis, inflammatory responses, tissue morphogenesis, and polarity [21,22]. In the Drosophila embryo, several downstream target genes of this signalling pathway are involved in dorsal closure and thorax formation $[23,24]$. The JNK pathway is required during imaginal disc regeneration $[17,18,25]$ and is activated near the wound as well as in cell death-induced regeneration [26]. The Wnt signalling cascade plays a key role in most aspects of embryonic development [27] and is involved in multiple processes during regeneration $[28,29]$. Induction of ectopic expression of wingless $(w g)$, a member of the Wnt family, mimics the pattern changes observed in leg imaginal discs after fragmentation (including regeneration), and promotes cell-fate plasticity such as leg-to-wing transdetermination [30,31]. The Notch signalling pathway is essential to determine cell fate and regulate pattern formation during embryonic and adult life [32]. It has been also reported to participate in the regeneration of zebrafish heart [33], Xenopus tail [6], mice muscle [34] and in transdetermination of imaginal discs [31]. Finally, $d p p$ is induced by the JNK pathway in the leading edge cells during dorsal closure [22] although no upregulation of its expression has been found during the process of regeneration [35].

The outcome of these signalling pathways is the transcriptional regulation of target genes that will elicit the ultimate response. Precisely which genes are required for the process of regeneration has been examined in the last few years by the use of genetic and molecular techniques in various model organisms (such as planarians, hydra, amphibians and zebrafish). For example, a large-scale RNAi-based screen was performed to survey gene function in planarian regeneration [36] and a global analysis of gene expression was carried out in Xenopus limb regeneration [37]. In Drosophila, a collection of lethal P-lacZ enhancer trap lines was used to screen for genes that function in leg disc regeneration [20]. Klebes et al. [31] reported the expression profiles of cells induced by ectopic $w g$ expression to transdetermine from leg to wing disc, thus generating a list of candidate regulators of cellular plasticity in flies. Despite these studies, however, it remains unclear whether regeneration requires the reactivation of earlier developmental genes or signalling pathways, or if it involves the activation of novel genes specific to the regeneration process. In an attempt to answer these questions we have taken a systematic approach and determined the expression profile of regenerating wing imaginal discs at different times after fragmentation and culture. By combining experimental and computational techniques, we have been able to decipher the transcriptional status of regenerating discs and link signalling circuits to gene regulation.

\section{Results and Discussion}

\section{Whole genome expression analysis of intact and} regenerating wing discs

Previous studies from our group showed that epithelial and cytoskeleton changes occur during the first 24 hours of regeneration [17] and that proliferation peaks two to three days after the cut [19]. To study different stages of the regenerative process we designed 12 microarrays containing 12,254 genes annotated in RefSeq from D. melanogaster [38]. Four microarrays (non cut, $\mathrm{NC} 0 \rightarrow \mathrm{NC24}$ ) were used to assess the effect of the implantation procedure in intact wing discs. The remaining eight were used to measure changes in gene expression in the first 24 hours after disc dissection and implantation (cut, $\mathrm{C} 0 \rightarrow \mathrm{C} 24$ ) and during the period between 24 hours and 72 hours after the cut (C24 $\rightarrow$ C72). The entire set of microarrays was normalized following the same protocol, extracting in each case the list of significant genes (at least two-fold change, false discovery rate (FDR)-corrected $P$ value $<0.05$, see Methods). The genes identified in these microarrays were functionally annotated using the Gene Ontology (GO terms [39]).

The number of genes whose expression was significantly modified during regeneration is shown in Table 1. More genes were reported in $\mathrm{C} 0 \rightarrow \mathrm{C} 24$ in comparison to $\mathrm{NCO} \rightarrow \mathrm{NC} 24$, which reflects the combination of regeneration events and the implantation effect at this early stage. In fact, half of the genes whose expression was significantly upregulated or downregulated during this period in cut discs were not detected in non-

Table 1 Total number of up and downregulated genes in $\mathrm{NCO} \rightarrow \mathrm{NC24}, \mathrm{CO} \rightarrow \mathrm{C2} 4$ and $\mathrm{C24} \rightarrow \mathrm{C72}$ microarrays

\begin{tabular}{lrrr}
\hline & NC0 $\rightarrow$ NC24 & C0 $\rightarrow$ C24 & C24 $\rightarrow \mathbf{C 7 2}$ \\
\hline Genes $\uparrow$ & 407 & 607 & 116 \\
\hline Genes $\downarrow$ & 356 & 576 & 165 \\
\hline TOTAL & 763 & 1183 & 281 \\
\hline
\end{tabular}


fragmented ones (44\% of 1,183 differentially expressed genes in $\mathrm{C} 0 \rightarrow \mathrm{C} 24$ were not found in $\mathrm{NCO} \rightarrow \mathrm{NC24}$ ). Conversely, most relevant genes in the intact discs transcriptome presented the same expression pattern in cut discs $(87 \%$ of 763 genes in $\mathrm{NCO} \rightarrow \mathrm{NC} 24$ were in $\mathrm{C} 0 \rightarrow \mathrm{C} 24)$. The number of genes in $\mathrm{C} 0 \rightarrow \mathrm{C} 24$ was also higher than in $\mathrm{C} 24 \rightarrow \mathrm{C} 72$ confirming the strong initial response during the first 24 hours.

Functional annotation of both $\mathrm{C} 0 \rightarrow \mathrm{C} 24$ and $\mathrm{NC} 0 \rightarrow \mathrm{NC} 24$ microarrays reveals significant enrichment in genes associated with apoptosis, response to stress, cytoskeletal activity, and JNK pathway regulation (Figure 1A), which agrees well with previous results reported for early regeneration of wing imaginal discs $[17,18]$. The cellular machinery required for gene expression (RNA processing and protein synthesis) seems to be blocked during the first 24 hours after implantation. We analyzed the set of genes displaying expression changes only in cut and implanted discs (200 upregulated and 220 downregulated genes in $\mathrm{C} 0 \rightarrow \mathrm{C} 24$ ), which presumably represents the early regeneration signature in wing imaginal discs. Many upregulated genes (Figure 1A) are associated with the immune response to other organisms and probably constitute a response to surgical manipulation. It has been reported that mechanical wounding is able to induce an antibacterial response that might prime the organism to fight what is perceived to be an increased likelihood of infection [40]. More importantly, we identified several genes involved in the Notch and Wg signalling pathways and transcription factor-encoding genes whose expression is increased only in cut discs during the first 24 hours (Additional file 1). Functional analysis of downregulated genes identified enrichment associated with multiple metabolic processes.

While direct comparison between upregulated and downregulated genes in $\mathrm{C} 0 \rightarrow \mathrm{C} 24$ and $\mathrm{NC} 0 \rightarrow \mathrm{NC} 24$ provides a qualitative description of both transcriptomes, GSEA (Gene Set Enrichment Analysis) is able to reconstruct a quantitative portrait of the functional differences between these microarrays. GSEA is a computational method that determines whether a defined set of genes (e.g. GO categories) shows statistically significant differences between two biological conditions (e.g. cut versus intact discs) [41]. Genes associated with a given GO category were ranked according to their expression profiles $(\mathrm{C} 0 \rightarrow \mathrm{C} 24$ versus $\mathrm{NCO} \rightarrow \mathrm{NC} 24)$. Then, the enrichment score (ES) was calculated to evaluate if the GO terms were randomly distributed or found at the extremes (left or right) of the ranked list. While GSEA analysis detected a significant enrichment in $\mathrm{C} 0 \rightarrow \mathrm{C} 24(P$ value $<0.01)$ of genes involved in Notch and Wg signalling pathways, several transcription factors and the immune response (Figure 1B), no particular categories were found to be

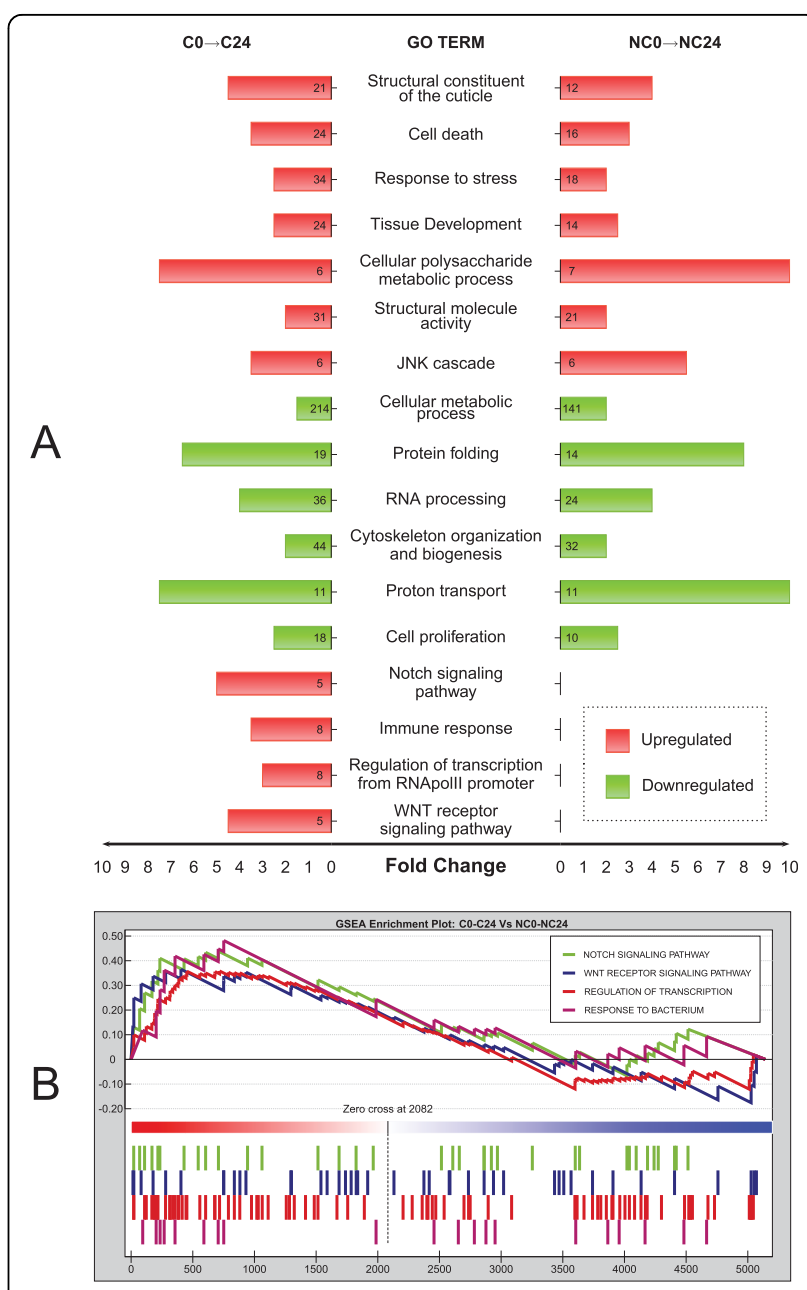

Figure 1 Whole genome expression analysis of cut (C) and uncut (NC) wing imaginal discs after 24 hours. (A) Gene ontology (GO) terms of upregulated (red) or downregulated (green) genes. The number of genes in each category in the microarrays is shown within the bars. The length of the bars indicates the fold change (enrichment in these transcriptomes compared to the whole genome, $P$ value $<0.001$ in all cases). (B) Enrichment plots for statistically significant GO categories. (Top) The Enrichment Score (ES) computed by GSEA is shown for each category. ES value reaches its absolute peak on the left side of the enrichment plot, indicating overrepresentation in $\mathrm{CO} \rightarrow \mathrm{C} 24$ compared with $\mathrm{NCO} \rightarrow \mathrm{NC24}$. The zero cross mark indicates the point in which the difference between expression in $\mathrm{CO} \rightarrow \mathrm{C} 24$ and $\mathrm{NCO} \rightarrow \mathrm{NC} 24$ is 0 . (Bottom) Coloured bars illustrate the position of genes belonging to each GO category ranked according to their expression values in C and NC discs.

specific only in intact discs. This observation strengthens the early regeneration signature identified by direct comparisons of upregulated and downregulated genes.

By comparing the differential gene expression between cut and uncut discs, we have been able to describe the implantation effect at the transcriptomic level. However, as biological processes governing disc regeneration may be pertinent for the implantation response, a clear 
distinction between $\mathrm{C} 0 \rightarrow \mathrm{C} 24$ and $\mathrm{NC} 0 \rightarrow \mathrm{NC} 24$ gene sets is rather difficult to make at this point. For instance, genes involved in apoptosis and regulation of the JNK cascade, which have been reported to be essential for imaginal disc wound healing and dorsal closure [17,24], were identified as upregulated in microarrays for intact discs. Implantation probably results in sufficient stress to trigger the JNK pathway and these genes cannot be eliminated as relevant. Moreover, members of the Notch and Wg signalling pathways, which show increased expression only in cut discs, have been previously reported in other regeneration systems [31,33]. As an alternative, the nonsurgical method for inducing tissue damage and regeneration $[26,28]$ emerges as a very powerful system not only to avoid the technical difficulties associated with disc transplantation but also to perform new molecular screens and validate our results.

Identification of genes with putative roles in regeneration We next examined the set of 281 genes showing expression changes in the $\mathrm{C} 24 \rightarrow \mathrm{C} 72$ microarrays and detected an enrichment of transcription factors during this second regeneration stage (Figure 2 and Additional file 2). When compared to $\mathrm{C} 0 \rightarrow \mathrm{C} 24$ experiments, we observed a significant increase in genes involved in the regulation of RNA metabolism and gene expression in the set of upregulated genes, whereas genes involved in apoptotic processes, structural activities and dorsal closure were augmented in the set of downregulated genes (Figure 2). These results suggest that the normal activity of imaginal discs, interrupted in response to dissection and implantation, is resumed during the 24-72 hours of regeneration. In addition, we detected functional categories associated with the immune system in both, upregulated genes (related to the stress response) and downregulated genes (related to the defense response to bacteria).

We performed GSEA analysis of $\mathrm{C} 0 \rightarrow \mathrm{C} 24$ and $\mathrm{C} 24 \rightarrow$ C72 microarrays in order to elucidate which GO categories are enriched in the full transcriptomes. The GSEA plot in Figure 3A shows the functional classes overrepresented in early regeneration. The results of that analysis confirmed the enrichments previously identified (Figure 2). Moreover, in addition to RNA processing and protein folding activities, GSEA analysis of $\mathrm{C} 24 \rightarrow \mathrm{C} 72$ identified an enrichment in genes associated with cell proliferation and chromatin remodeling processes during late regeneration of wing discs (Figure 3B).

To further characterize the regeneration process, we defined four classes of genes according to their expression levels (Figure 4): Class I, genes showing differential expression only in $\mathrm{C} 0 \rightarrow \mathrm{C} 24$; Class II, genes with differential expression only in $\mathrm{C} 24 \rightarrow \mathrm{C} 72$; Class III, genes displaying changing expression levels between the two

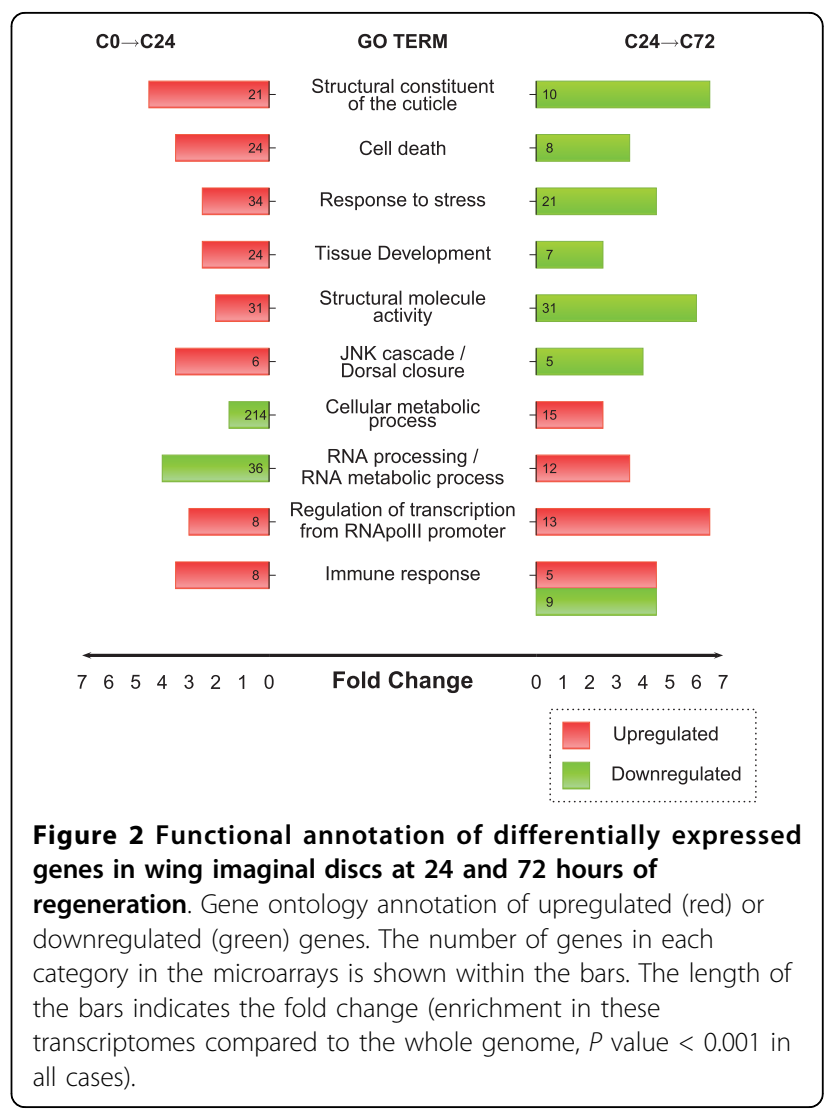

periods; and Class IV, genes that steadily increase or decrease their expression levels. For each class, we graphically defined their characteristic functional signature using GSEA analysis (for a list of representative genes, see Figure 5 and Additional file 3).

Class I genes show a significant change, either increasing or decreasing expression between 0 hours and 24 hours after the cut, but remain constant during the second period of time. Most genes in $\mathrm{C} 0 \rightarrow \mathrm{C} 24$ present this expression pattern (82\% of upregulated genes and $93 \%$ of downregulated genes, Additional file 4). As expected, we found upregulated genes associated with dorsal closure, the JNK cascade, MAP kinase activity, and the Notch and Wg signalling pathways. In addition, other genes associated with imaginal disc development, immune response, and apoptotic processes were detected. Moreover, we identified several downregulated genes in this class associated with growth regulation or involved in chromatin remodeling and wing disc development. This category is a representation of the additive response of the implantation effect and the process of regeneration.

Class II genes display increased or decreased expression between 24 and 72 hours but remain constant in $\mathrm{C} 0 \rightarrow \mathrm{C} 24$. Approximately half of the genes in $\mathrm{C} 24 \rightarrow \mathrm{C} 72$ showed this expression pattern $(44 \%$ of upregulated 
genes and $49 \%$ of downregulated genes, Additional file 4). A significant enrichment of upregulated transcription factors was observed in Class II, including Sox box protein 15 (Sox15 or SoxF), Enhancer of split (E(spl)) and Medea (Med). SoxF codes for a transcription factor involved in the $\mathrm{Wg}$ signalling pathway that has been linked to control of proliferation in Drosophila [42] and also skeletal muscle regeneration in mice [43]. $E(s p l)$ is an essential Notch signalling pathway mediator [32] and $M e d$, a component of the $d p p$ pathway [44]. Moreover, several chromatin regulators showing increasing expression levels are also included in this class. Brahma associated protein $60 \mathrm{kD}$ (Bap60) and Dalao are components of the Brahma complex involved in chromatin remodeling [45] and Nucleosome assembly protein 1 (Nap1) has been implicated in nucleosome assembly [46]. Bap60 and Sox 15 have been also identified in microarrays of leg disc transdetermination [31]. Activation of these genes together with the presence in this class of splicing and translation initiation factors indicates that the normal RNA processing machinery resumes its activity in the disc at this stage. In contrast, genes involved in the wound healing response and cytoskeletal organization processes were downregulated, presumably indicating that cell shape changes and cytoskeletal reorganization described in early healing have been accomplished.

Class III represents the set of genes whose expression changed dramatically, from significant upregulation to downregulation or vice versa. Up to 48 genes were identified as upregulated in $\mathrm{CO} \rightarrow \mathrm{C} 24$ and downregulated in $\mathrm{C} 24 \rightarrow \mathrm{C} 72$ (29\% of downregulated genes in C24 $\rightarrow \mathrm{C} 72$, Additional file 4) but only two genes had the opposite expression pattern. This module represented only $8 \%$ of upregulated genes in $\mathrm{C} 0 \rightarrow \mathrm{C} 24$ (Additional file 4). Class III was, in fact, enriched in genes associated with the stress response, response to stimuli, defense response, and structural activities, as well as several downstream targets of the JNK regulatory cascade. For example, we found the Krüppel-like transcription factor cabut ( $c b t)$ $[47,48]$, the Collagen type IV $(C g 25 C)$ gene related to dorsal closure, and Drosomycin (Drs), Immune induced molecule I (IM1), Transferrin (Tsf1) and Gadd45, which play a role in the defensive response $[40,49]$. The increase in the expression of other genes that play a defensive function during the first 24 hours and the subsequent decrease up to 72 hours correlates well with their role in the defensive immune response. Furthermore, the slamdance $(s d a)$ gene, belonging to this category, has also been identified in other regeneration screens using leg imaginal discs [31]. Most genes identified in Class III exhibit an increase/decrease pattern of expression during regeneration. These genes could account for the cellular responses to injury, which would then be switched off once wound healing is completed.
Finally, Class IV includes genes whose expression remains significantly increased or decreased throughout the whole process, indicating their relevance during the 72 hours after the cut. A large fraction of upregulated and downregulated genes in $\mathrm{C} 24 \rightarrow \mathrm{C} 72$ (56\% of upregulated genes and $22 \%$ of downregulated genes, Additional file 4) had the same expression pattern observed in $\mathrm{C} 0 \rightarrow \mathrm{C} 24$. While both microarrays were characterized by an enrichment of upregulated genes whose products are involved in apoptotic processes and transcription factors, the set of downregulated genes was rich in products with defensive response functions. Among the genes whose expression pattern was upregulated throughout the experiment, we found headcase ( $h d c$ ) and regucalcin, which were previously identified in imaginal disc regeneration [31]. In addition, we detected the cryptocephal ( $\mathrm{crc}$ ) gene, different chromatin remodeling factors such as absent, small, or homeotic discs 2 (ash2) and modifier of $m d g 4(\bmod (\operatorname{mdg} 4))$ as well as three basic helix-loop-helix (bHLH) transcription factors (bigmax, $H L H m 3$ and $H L H m 7$ ), indicating again that transcriptional regulation plays a critical role in regeneration. Finally, Inhibitor of apoptosis 2 (Iap2), longitudinals lacking (lola), and Thor are related to the immune response. $\mathrm{Crc}$ is a downstream target of the JNK pathway implicated in wound healing $[22,50]$ and it has been reported that the activity of Thor in aging also depends on the JNK pathway [51]. The set of genes that remained downregulated throughout the 72-hour period comprised a group of actin and heat shock proteins that were probably activated just after the injury, and the endopeptidases tolloid (tld) and tolkin (tok), involved in imaginal disc morphogenesis.

\section{Transcriptional regulators acting in early and late regeneration}

Among the plethora of genes identified as having altered expression during the regeneration process, we draw attention to the potential role played by those associated with transcriptional regulation. We first analyzed the putative targets of several transcription factors which are candidate participants in disc wound healing and regeneration. We computationally searched for binding sites of these transcription factors in promoter sequences of misregulated genes, using the genomes of 12 Drosophilas [52] to solidify the predictions (conserved sites at least in D. pseudoobscura and four additional Drosophilids, enrichment calculated in comparison to the total number of conserved sites of each class in the $D$. melanogaster genome, see Methods).

The JNK signalling pathway activates the AP1 (Activator Protein 1) transcription factor, a dimer of jun and fos $[53,54]$. We searched for AP1 binding sites in the promoters of upregulated and downregulated genes in 


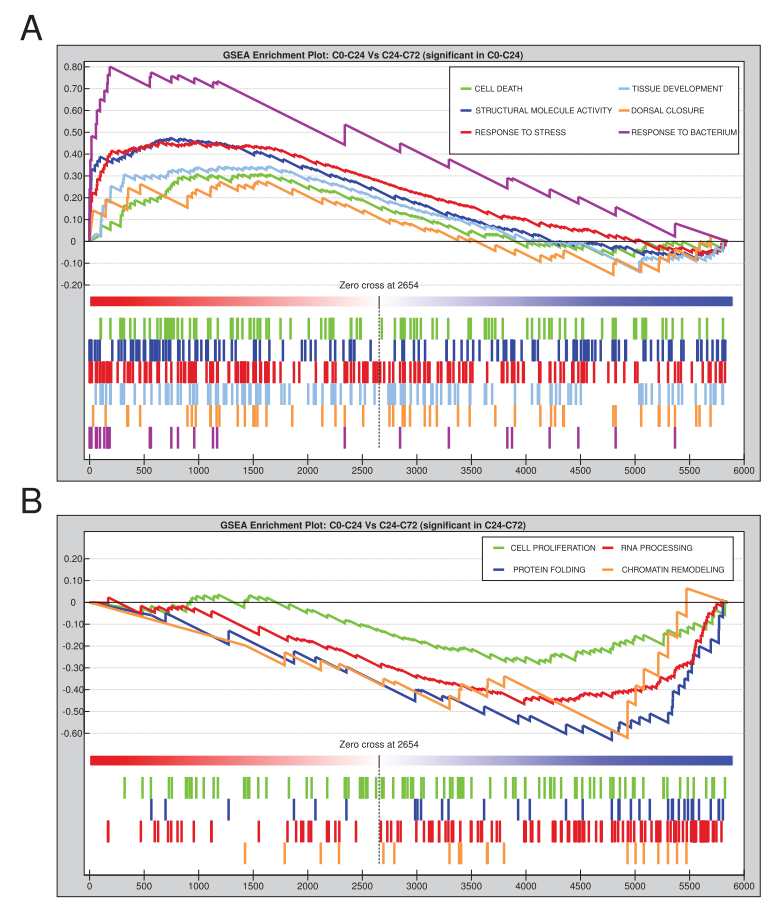

Figure 3 Gene set enrichment analysis of differentially expressed genes in wing imaginal discs at 24 and 72 hours of regeneration. (A) Enrichment plots for statistically significant $\mathrm{GO}$ categories in $\mathrm{CO} \rightarrow \mathrm{C} 24$. ES value reaches its absolute peak on the left side of the enrichment plot, indicating overrepresentation of these categories compared with $\mathrm{C} 24 \rightarrow \mathrm{C} 72$. (B) Enrichment plots for statistically significant $\mathrm{GO}$ categories in $\mathrm{C} 24 \rightarrow \mathrm{C} 72$. ES value reaches its absolute peak on the right side of the enrichment plot, indicating overrepresentation of these categories compared with $\mathrm{C} 0 \rightarrow \mathrm{C} 24$. Genes in each $\mathrm{GO}$ category ranked according to their expression values in both time points are shown as coloured bars. The zero cross mark indicates the point in which the difference between expression in $\mathrm{C} 0 \rightarrow \mathrm{C} 24$ and $\mathrm{C} 24 \rightarrow \mathrm{C} 72$ is 0 .

$\mathrm{C} 0 \rightarrow \mathrm{C} 24$ (Figure 6). We found putative binding sites in the promoters of 24 upregulated genes conserved in several Drosophila species (371 genes identified in the whole genome, $P$ value $<10^{-6}$ ). Interestingly, 11 out of these 24 genes were reported only in cut discs. The number of AP1 predictions in the downregulated genes was not statistically significant. This was as anticipated, given the role of AP1 as a transcriptional activator. The number of AP1 occurrences was not significant in the upregulated genes of the $\mathrm{C} 24 \rightarrow \mathrm{C} 72$ microarrays, while 15 AP1 binding sites were identified in 12 downregulated genes $\left(P\right.$ value $<10^{-8}$ ). When correlating these predictions with the gene classes previously established, in addition to the expected abundance of Class I genes, we identified a significant enrichment of Class III genes. Despite a small amount of misregulated genes belong to this class (Additional file 4), we identified AP1 sites in six Class III genes in both $\mathrm{C} 0 \rightarrow \mathrm{C} 24$ and $\mathrm{C} 24 \rightarrow \mathrm{C} 72$ microarrays $(P$ value $<0.001$ and $P$ value $<0.05$, respectively). These results suggest that the JNK pathway regulates the expression of Class I and Class III genes through AP1 during the first few hours of wing disc healing and that its activity decreases during later stages of regeneration. As expected, different elements of the JNK pathway have been identified in our expression profiles, confirming its activation during regeneration. The phosphatase puckered (puc) has been used as a molecular readout of the activated JNK pathway and its expression seems directly controlled by AP1. In imaginal disc fragmentation experiments, the expression of puc is activated in several rows of cells near the wound edges at 5 hours after the fragmentation, peaking at 12 hours and decreasing from 24 hours onwards, as the wound is healed $[17,19]$. Differences in puc expression would therefore be very difficult to detect at the time points used in this study. However, by using bioinformatics analysis we have identified a significant enrichment of AP1 sites in the promoters of several other genes with differential expression only in cut discs that are pyhlogenetically conserved in multiple Drosophila species, suggesting that they could be direct targets of the JNK pathway.

Many members of the $(E(s p l))$ gene complex show a significant increase in their expression levels during wound healing and regeneration stages. In particular, we observed that the $E(s p l)$ gene is upregulated in $\mathrm{C} 24 \rightarrow \mathrm{C} 72$ microarrays (Class II). E(spl) is a bHLH transcription factor that binds regulatory sequences containing the E-box palindromic motif CACGTG $[55,56]$. We performed a search of E-boxes in the promoters of misregulated genes in $\mathrm{C} 24 \rightarrow \mathrm{C} 72$ (Figure 6). We identified six evolutionarily conserved E-boxes in the promoters of downregulated genes (346 genes in the whole genome of $D$. melanogaster, $P$ value $<0.01)$. Four of those six genes display an expression pattern fitting Class III genes $(P$ value $<0.05)$, in contrast to the lower total number of genes in this class in $\mathrm{C} 24 \rightarrow \mathrm{C} 72$ (Additional file 4). Although these results suggest that the genes identified are potential downstream targets of the Notch pathway, it should be pointed out that other proteins, such as $\mathrm{dMyc}$, could also recognize the general consensus sequence for the E-box element [57].

Finally, besides transcription factors we have also identified genes that encode for chromatin remodelers. This finding highlights the importance of transcription and chromatin remodeling in regeneration and is consistent with similar studies [31]. It has been demonstrated that suppression of Polycomb group (PcG) proteins by JNK induces transdetermination in Drosophila imaginal discs and that this downregulation is directly controlled by the JNK signalling pathway [25]. We have not found PcG genes in our screen. Instead, the majority of chromatin regulators encode proteins that may play a 


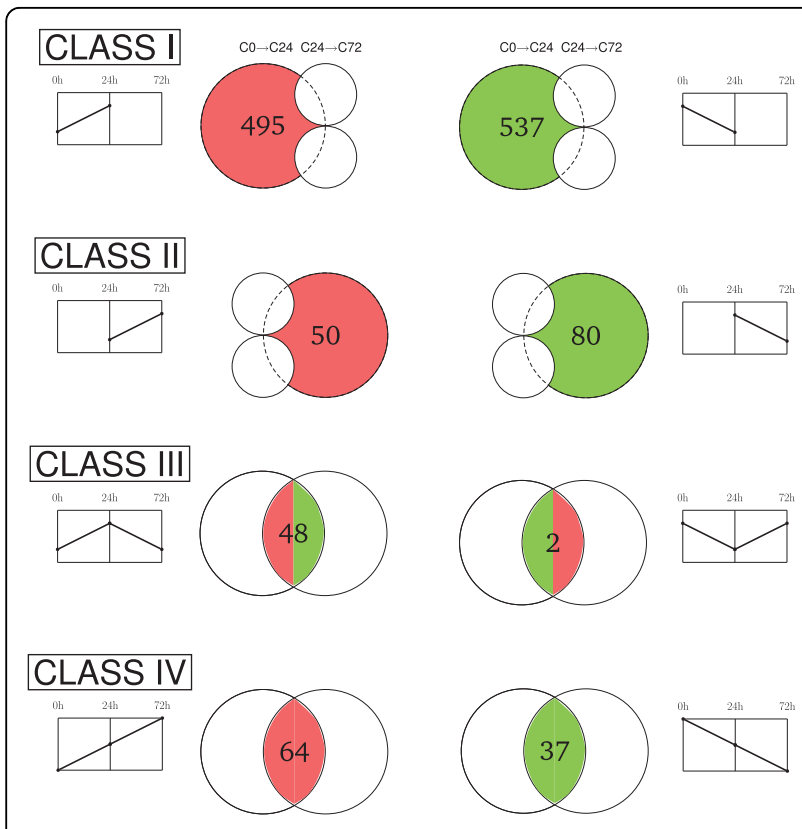

Figure 4 Classification of differentially expressed genes involved in wing imaginal disc regeneration. According to the expression changes in early and late regeneration stages, genes in the transcriptomes were organized in four classes: Class I, genes with differential expression only in the first 24 hours; Class II, genes with differential expression only between 24 and 72 hours; Class III, genes with a significant difference between the two time periods; Class IV, genes with a sustained increase or decrease in their expression levels during regeneration. Intersections of upregulated genes (in red) and downregulated genes (in green) in a particular class are depicted using Venn diagrams. For each intersection, we display the number of genes and a generic pictogram representing the gene expression trend in $\mathrm{C} 0 \rightarrow \mathrm{C} 24$ and $\mathrm{C} 24 \rightarrow \mathrm{C} 72$.

general role as transcriptional activators. Among these, Ash2, a member of the trithorax group (trxG), is required for histone $\mathrm{H} 3$ trimethylation at lysine 4 (H3K4me3) and belongs to multiple methylation complexes [58,59], and BAP60 and Dalao are members of the Brahma complex $[60,61]$. The transcriptional activation of this small number of cofactors may lead to the enzymatic activation of several proteins involved in chromatin activity. According to our results, global transcription slows at the beginning of regeneration but resumes concurrent to wound repair.

\section{Requirement of transcription factors and chromatin remodelers in regeneration}

We expect impairment on the ability to regenerate in mutants for the genes identified in our molecular screen. The requirement of the JNK pathway in wing imaginal disc regeneration has already been described [17-19,26] and alterations in the expression levels of Notch members have also been reported [31]. After validating the changes in expression levels of selected genes by quantitative PCR (Additional file 5), we investigated their involvement in regeneration. Wing discs from heterozygous flies (the homozygous condition being lethal) were fragmented as above, implanted and recovered after 24 and 48 hours (Figure 7). Although healing did not seem to be affected in $N^{I 1 N-t s 2}$ mutant discs, proliferation, measured by counting the number of mitotic cells labelled with anti-Phospho-Histone3 (PH3), was impaired. We also analyzed regeneration in imaginal discs from heterozygous flies with a deficiency of all $E$ (spl) complex genes. Despite the fact that wound closure did not seem to be compromised, a significant decrease in proliferation occurs at 24 and 48 hours. Moreover, to inquire into the role of Class III genes in regeneration, we examined $c b t$ mutant discs. Even though the discs healed properly, there was lower proliferation in analyzed discs. Finally, since the category of chromatin regulators is significant (this report and [31]), we examined the requirement for ash2, a Class IV member, in regeneration. Heterozygous discs for the ash $2^{I I}$ allele were smaller and showed wound healing defects at 24 hours, probably hampering the proper assessment of their proliferative capacity. Although proliferation seems to be affected at 48 hours, it is probable that the absence of regeneration in these mutant discs is due to healing impairment.

\section{The transcription factor Cbt as an example of Class III genes}

Most genes identified in Class III display a characteristic increase/decrease pattern of expression during regeneration, suggestive of tight regulation associated with the requirement of the proteins encoded by these genes in a particular window of time. As a member of Class III, $c b t$ was upregulated during the first 24 hours after disc fragmentation, decreasing dramatically in the following 48hour period. As already suggested by Muñoz et al. [47], we found an AP1 binding site present in the proximal promoter of $c b t$ conserved in multiple Drosophila species (Figure 8A), which indicates that is directly regulated by AP1. In third instar larvae, $c b t$ is ubiquitously expressed in the wing disc (Figure 8B, C), and according to our predictions, we observed an increase in the level of expression of $c b t$ after activating the JNK pathway in the posterior compartment (Figure 8D). More importantly, we detected an increase in the regenerating tissue, confirming the induction of its expression after injury (Figure 8E). As an alternative method to avoid microsurgery, regeneration was induced by triggering apoptosis in the wing disc in a spatially and temporally regulated manner. Recent reports have already shown that cell death can be locally induced in certain domains of the disc using the Gal4/UAS binary system in combination with $\mathrm{Gal}^{\mathrm{ts}}[26,28]$. The use of the salm-Gal4 


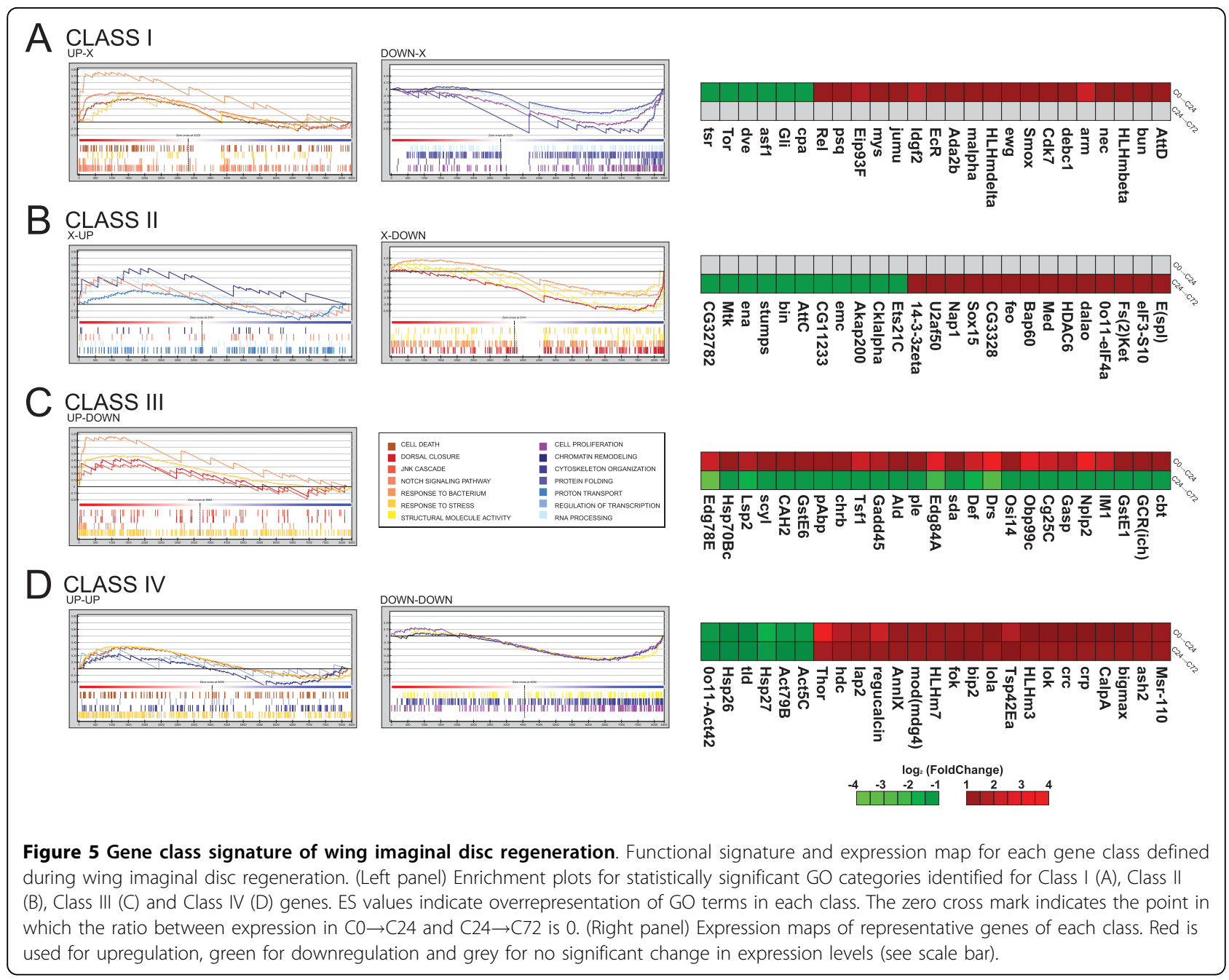

construct to drive expression of the pro-apoptotic gene reaper (rpr) results in a region of dead cells in the spalt (sal) domain. Higher levels of cbt expression can be detected in the regenerating cells that close the wound apically (Figure $8 \mathrm{E}-\mathrm{H}$ ). We have already demonstrated that during cell death-induced regeneration, the JNK pathway is activated at the leading edges of healing tissue, and is required in the living cells for the regulation of healing and regenerative growth [26]. Our results point to the transcription factor Cbt as a crucial downstream mediator gene of JNK signalling during microsurgery or cell death-induced regeneration.

Although further experiments are required, it is possible that $\mathrm{E}(\mathrm{spl})$ binds to the E-boxes identified in the promoters of $c b t$ and other members of Class III genes contributing to their downregulation in the 24-72 hours period. In fact, in addition to $c b t$ and CG10337, we found three more genes of this class $(\mathrm{Cg} 25 \mathrm{C}$, Gadd 45 and ple) containing conserved AP1 sites and E-boxes in their promoter regions when we extended our analysis up to $10 \mathrm{~Kb}$ upstream of the TSS (Additional file 6). All these genes are precisely known JNK targets $[40,47,62,63]$. In Drosophila, the Notch pathway is known to participate in the regulation of growth in the wing [64] and a relationship between both the JNK and Notch pathways has recently been documented in tissue homeostasis in aging flies [65]. In that study, it was shown that tissue regeneration in the fly intestinal epithelium depends on a sensitive balance between JNK and Notch signalling events regulating stress responses, stem cell proliferation, and cell differentiation. Therefore, it is tempting to speculate that both JNK and Notch pathways cooperate by regulating the transcriptional activity of the same set of genes during wound healing and regeneration of wing imaginal discs.

\section{Conclusions}

By determining expression profiles at different times of regeneration, we have been able to identify early and late genes involved in the process. The onset of wound 


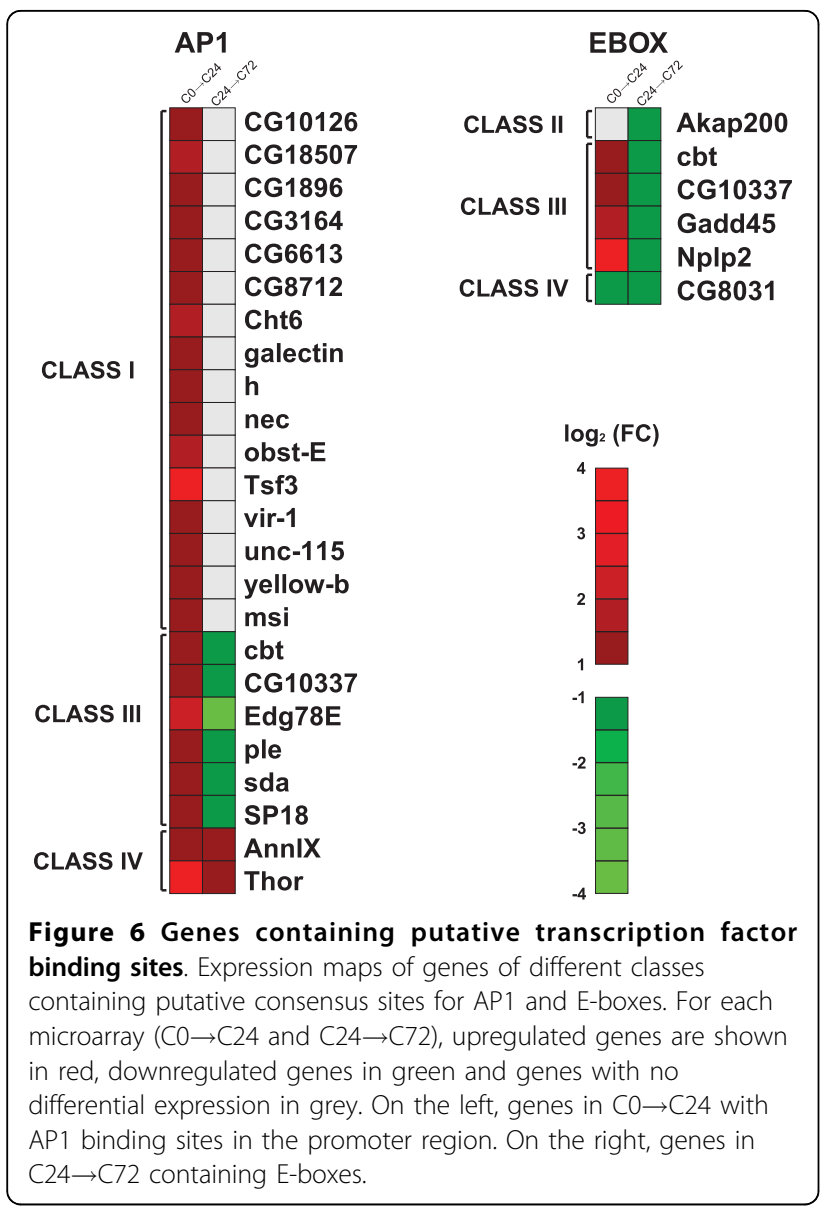

healing is the first necessary step for regeneration [66] and the role of the JNK pathway in this type of processes has been widely documented $[17,19,25]$. Different elements of the JNK pathway have been identified in our expression profiles, confirming its activation during regeneration. Our analysis show a significant enrichment of AP1 sites in the promoters of several genes with differential expression only in cut discs, suggesting that they could be direct targets of the JNK pathway. Several genes identified in our work encode for transcription factors, some of them of known signalling pathways, and chromatin remodelers. This finding highlights the importance of transcription and chromatin dynamics in regeneration and is consistent with similar studies [31]. A comprehensive description of the regeneration process will be enriched in the future by incorporating information complementary to our expression data. Thus, additional biological processes that are not directed by transcriptional responses, such as translational control and subcellular localization, should be recognized. However, the characterization of the relative contribution of critical pathways [67], or more precisely, of key genes may ultimately lead to the identification of therapeutic targets for use in regenerative medicine.

\section{Methods}

\section{Drosophila strains and experimental conditions}

All Drosophila strains and crosses were kept on standard media at $25^{\circ} \mathrm{C}$. For microarray and qRT-PCR experiments, imaginal disc regeneration was induced in the $w^{1118}$ ISO; 2iso; 3iso isogenic line from the DrosDel collection [68]. The following strains were used: CS; ash $2^{I 1} /$ TM6C [69]; $N^{I 1 N-t s 2}$ rb'; FRT82gro $^{+}$: Df(3R) gro $^{\text {b32.2 } / T M 6 B ~(a ~ c o m p l e t e ~ d e f i c i e n c y ~ o f ~ a l l ~} E(s p l)$ complex genes, in this paper referred to as $\operatorname{Df}(E(s p l)) ; c b t^{E P}$ (2)2237E1 /CyO-twi:GFP [47]; en-Gal4;Gal80 ${ }^{\text {ts }} / \mathrm{SM6a-}$ TM6B; UAS-hep ${ }^{\mathrm{CA}}$. All strains were kept at a constant temperature of $25^{\circ} \mathrm{C}$, with the exception of $\mathrm{Notch}^{I 1 N-t s 2}$, which was kept at $17^{\circ} \mathrm{C}$ until the dissection of discs and then at $25^{\circ} \mathrm{C}$ from just after implantation until the end of the experiment.

For cell death induction, UAS-rpr $/ \mathrm{Gal}^{\mathrm{ts}}$; salm-Gal4 flies were used as described [26]. Larvae were kept at $17^{\circ} \mathrm{C}$ to avoid $r p r$ expression until third instar larvae (approximately 120 hours after egg laying). Next, they were shifted to $29^{\circ} \mathrm{C}$ to activate $r p r$ expression for 10 hours, and then larvae were dissected and fixed with $4 \%$ formaldehyde.

\section{Imaginal disc manipulation and labeling of mitosis}

Imaginal disc manipulation, either of wild type or mutant discs, was performed as described previously [17]. Wing discs were removed from third instar larvae and a $90^{\circ}$ sector was dissected out from the posterior (P) compartment, leaving a 3/4 anterior fragment. Experimental and control (uncut) discs were implanted into recently eclosed Canton $\mathrm{S}$ females and kept at $25^{\circ} \mathrm{C}$. Regenerating fragments were recovered at 24 and 48 hours after implantation, fixed with $4 \%$ paraformaldehyd and immunostained following standard protocols with anti-PH3 (1:1000, Upstate Biotechnology, Inc), FITC-conjugated goat anti-rabbit secondary antibody (1: 200, Jackson Immunoresearch, Inc.) and TOPRO3 (Molecular Probes, Inc) for nuclei staining. Imaginal discs were mounted in SlowFade Light Antifade (Molecular Probes, Inc.) prior to confocal analyses (Leica $\mathrm{SPE})$. Images were treated with Image $(\mathrm{NIH})$ and Adobe Photoshop software. For analysis of wound healing and proliferation, at least 10 discs were analyzed for each condition. The number of $\mathrm{M}$-phase cells near the wound was determined using Image (NIH) software. We used SPSS Statistics 17.0 for statistical analysis.

\section{In situ hybridization}

In situ hybridization of wing imaginal discs fixed with $4 \%$ formaldehyde was performed as described previously [70]. $c b t$ sense and antisense RNA probes were synthesized using a complete cDNA (a gift from N. Paricio) with DIG RNA labeling Mix (Roche, Inc.) and 

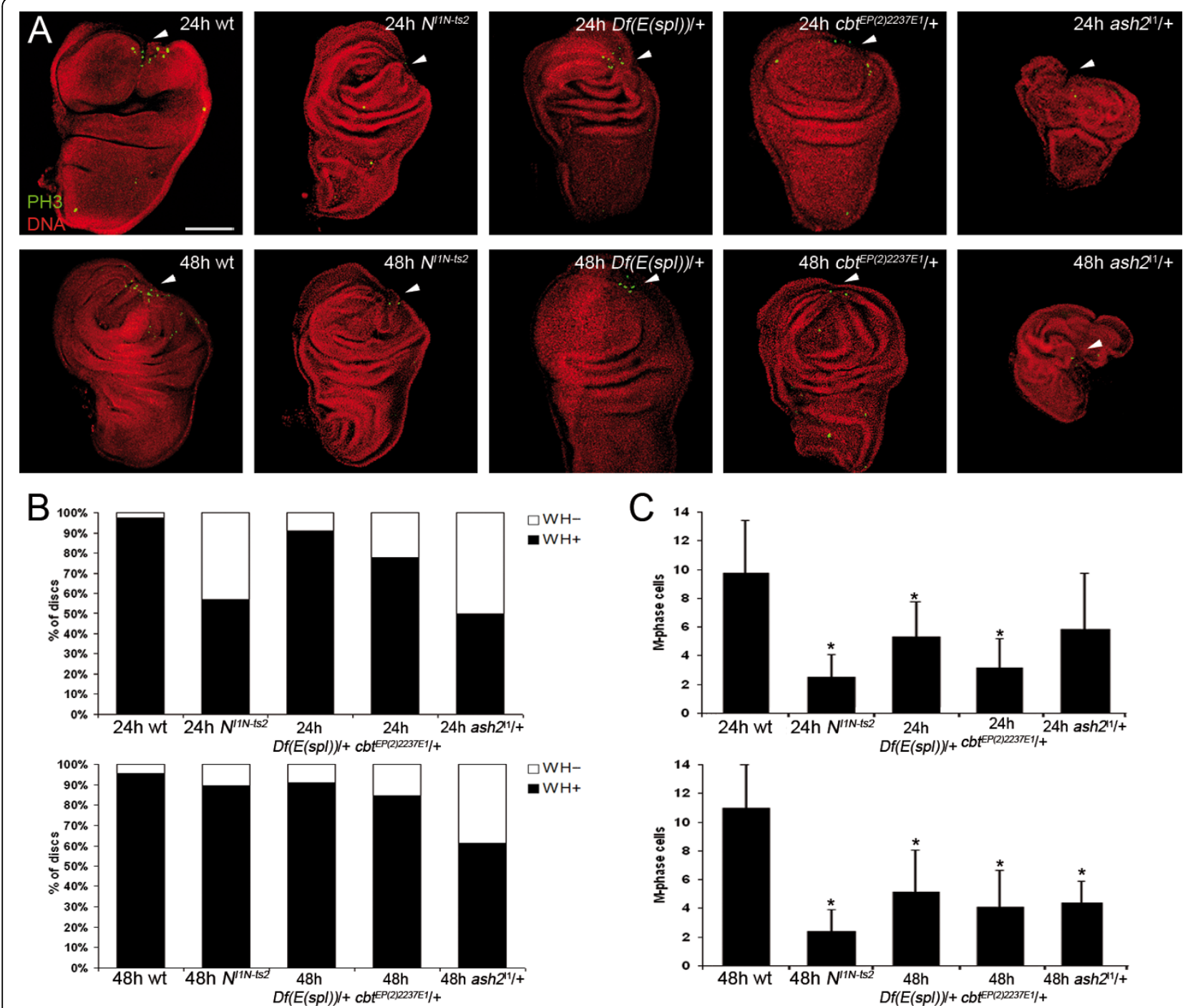

Figure 7 Involvement of the Notch pathway, $\boldsymbol{c b t}$ and $\boldsymbol{a s h} \mathbf{2}$ in wing imaginal disc regeneration. Wound healing (WH) and mitosis (M) in blastemas of Notch pathway, cbt and ash2 mutants. (A) Regenerating imaginal discs from wild-type (wt); $N^{1 / N-t s 2} ; \operatorname{Df}(E(s p /)) /+; c b t^{E P(2) 2237 E 1} /+;$ and ash $2^{11} /+$. Staining of mitosis (green) and nuclei (red). Scale bar $=100 \mu \mathrm{m}$. Upper panels show 24-hour regenerating discs; lower panels, 48-hour regenerating discs. Arrowheads point to the wound vertex. (B) Percentage of discs with correct wound closure (black) and absence of closure (white). (C) Number of M-Phase cells in the blastema region at 24 and 48 hours. Asterisk indicates differences between wt and mutants discs ( $P$ value < 0.005)

hydrolyzed prior to hybridization. An antibody conjugated with alkaline phosphatase (Roche, Inc.) was used against Digoxigenin probes. NBT/BCIP (Roche, Inc.) was used to develop in situ hybridizations and fast red tablets (Roche, Inc.) for fluorescent in situ hybridization. Discs were analyzed with a Leica DMLB fluorescent microscope and a Leica SP2 confocal microscope.

\section{Quantitative RT-PCR analysis}

Total RNA was extracted using the Mini RNA Isolation I Kit ${ }^{\mathrm{mm}}$ (Zymo Research Corp., CA, USA). Reverse transcription reactions with $500 \mathrm{ng}$ of RNA isolated from regenerating discs were used to synthesize cDNA with M-MLV reverse transcriptase (Invitrogen Corp., Carlsbad, CA, USA) according to the manufacturer's instructions. The qRT-PCR was performed with an ABI PRISM 7700 following the recommended protocol (Applied Biosystems, Foster City, CA, USA). Each sample was replicated three times and average values were used for further analysis. Data were analyzed by the $\Delta C T$ method and normalized by subtracting the value of the geometric average of three control genes (dia, $m R p L 9$ and ptp61F) obtained using geNorm software [71]. TaqMan primers and probes designed and synthesized by Applied 


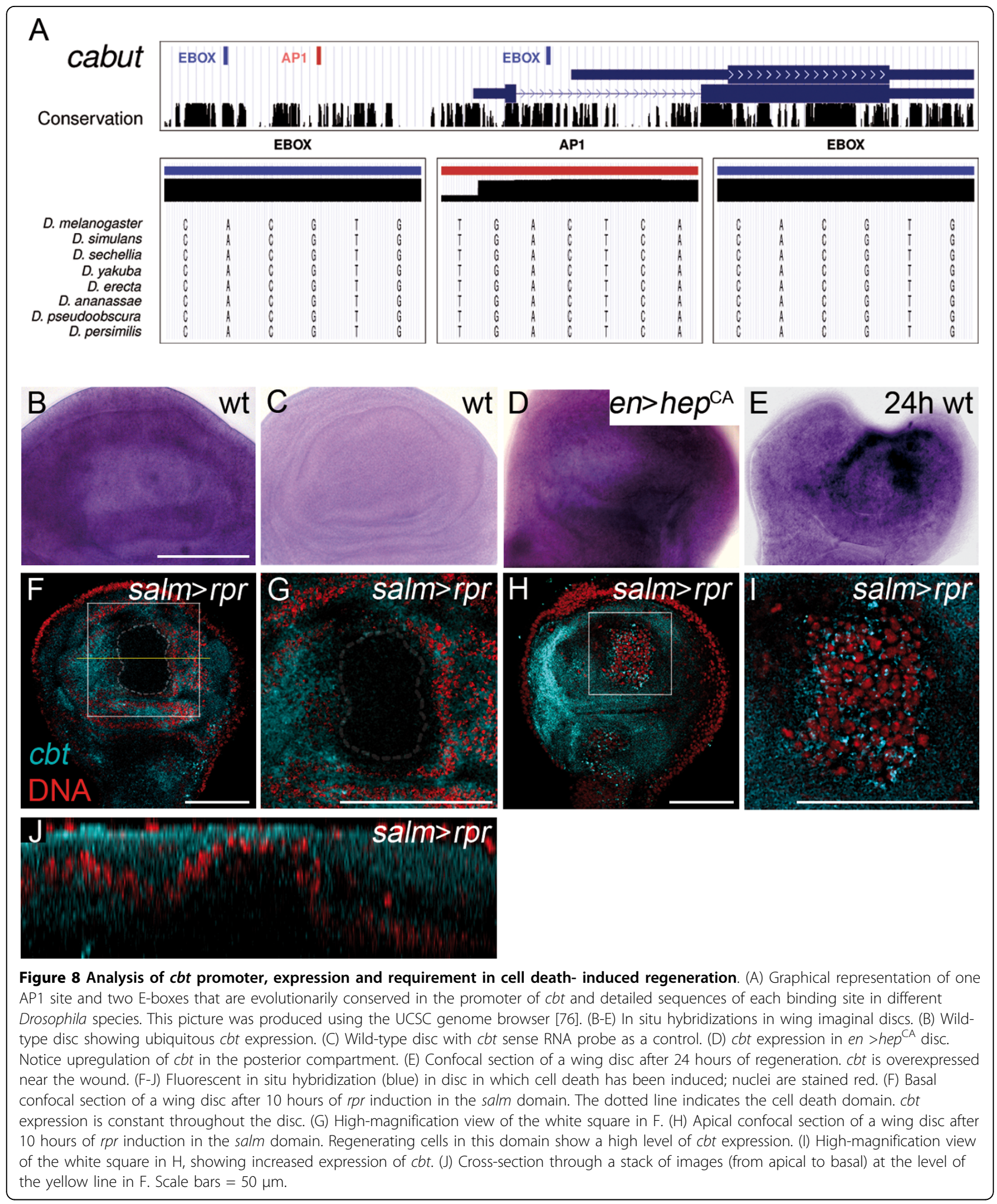


Biosystems for this analysis were: Dm02150755_g1 (ash2); Dm01800197_s1 (cbt); Dm02151501_s1 (E(spl)); Dm01821420_m1 (Sox15); Dm02151361_g1 (tld), Dm01811206_g1 (dia); Dm02135860_s1 (mRpL9); Dm 0183210_g1 (ptp61F).

\section{Microarray analysis}

Microarrays were printed at the Plataforma de Transcriptòmica (SCT-PCB, Universitat de Barcelona, Spain) using the Drosophila genome Oligo Set version 1.1 (Operon Biotechnologies Inc., Huntsville, AL., USA) as described previously $[69,72]$ (GEO platform number GPL3797). Total RNA was extracted as described above from wing discs recovered after 0,24 and 72 hours for cut discs, and at 0 and 24 hours for uncut discs. At least two independent RNA extractions were carried out. In the case of cut discs, RNA extracted after 24 hours of implantation was used as a common reference and therefore three pair-wise comparisons were set: $\mathrm{C} 0 \rightarrow \mathrm{C} 24, \mathrm{C} 24 \rightarrow \mathrm{C} 72$ and $\mathrm{NC} 0 \rightarrow \mathrm{NC} 24$. Four microarrays were hybridized for each experiment in biological replicate pairs including dye swaps to take dye bias into account. Microarray analyses were performed as described previously [72]. GenePix Results (GPR) data files were obtained for each microarray with an Axon 4000B scanner and GenePix Pro 6 (Molecular Devices Corp., Sunnyvale, CA, USA). All GPR files were analyzed with the Limma package from BioConductor $[73,74]$ using the same criteria. Array normalization was carried out independently for each set of four arrays using the mad method from OLIN, and a linear model was fitted and FDR corrected [73]. We obtained a list of genes that displayed at least two-fold differential expression (FDR-corrected $P$ value $<0.05$ ). Further experimental and statistical details together with raw and normalized data can be accessed through NCBI's Gene Expression Omnibus [75] series number GSE17408.

All gene sets have been mapped in the genome of $D$. melanogaster using the RefSeq track of the UCSC genome browser [76] annotations (genome assembly dm3, April 2006). We used the TermEnrichment tool from the AmiGO suite [77] to assess the statistical significance of GO term enrichments on each list of genes using the whole genome as a second reference set $(P$ value $<0.001$, each enrichment must contain at least five genes). We employed the program GSEA [41] to perform gene-set-enrichment analyses in the full transcriptome of each microarray (rank function: difference of expression values). The Enrichment Score (ES) was calculated by walking down the ranked list, increasing the cumulative sum when a gene is present in a given GO category and decreasing it if a gene is not (see [41] for further details).

\section{Promoter characterization}

We extracted 1,000 nucleotides upstream of the transcription start site of each gene according to RefSeq annotations in the UCSC Genome browser [76]. Using the predictive models published in the literature for AP1 and $\mathrm{E}(\mathrm{spl})[54,55]$, we used the MatScan program [78] to obtain the list of putative transcription factor binding sites on the set of gene promoters. We converted these predictions into the UCSC custom track format to map them along the D. melanogaster genome. Using the Conservation track (multiple alignment of Drosophila species), we filtered out the predictions that were not conserved in at least five species (including D. pseudoobscura or more distant species). We randomly sampled 10,000 datasets containing the same number of genes of each up or downregulated gene sets, using a Ztest to evaluate the statistical significance on each set of predictions in comparison to the whole genome.

\section{Additional material}

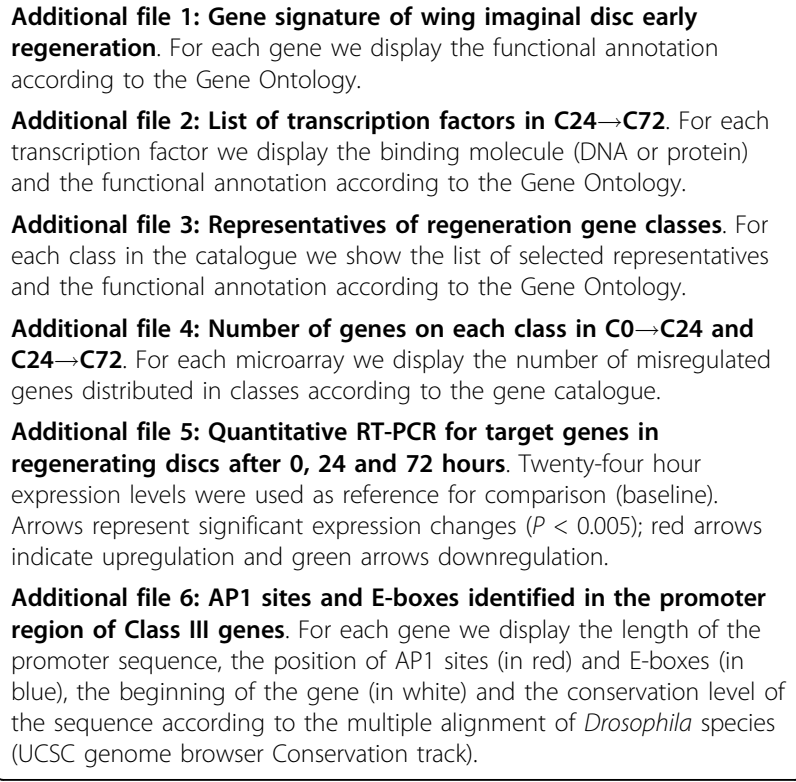

Additional file 3: Representatives of regeneration gene classes. For each class in the catalogue we show the list of selected representatives and the functional annotation according to the Gene Ontology.

Additional file 4: Number of genes on each class in $\mathrm{CO} \rightarrow \mathrm{C24}$ and $\mathbf{C 2 4} \rightarrow \mathbf{C 7 2}$. For each microarray we display the number of misregulated genes distributed in classes according to the gene catalogue.

Additional file 5: Quantitative RT-PCR for target genes in regenerating discs after $\mathbf{0 , 2 4}$ and $\mathbf{7 2}$ hours. Twenty-four hour expression levels were used as reference for comparison (baseline). Arrows represent significant expression changes $(P<0.005)$; red arrows indicate upregulation and green arrows downregulation.

Additional file 6: AP1 sites and E-boxes identified in the promoter region of Class III genes. For each gene we display the length of the promoter sequence, the position of AP1 sites (in red) and E-boxes (in blue), the beginning of the gene (in white) and the conservation level of the sequence according to the multiple alignment of Drosophila species (UCSC genome browser Conservation track).

\section{Acknowledgements}

We thank J. Casanova and C.B. Byars for critically reading the manuscript, $H$. Auer for insightful suggestions for the real time PCR and N. Paricio and F. Schweisguth for fly stocks. We also thank the Program for Genomic Applications at the Institute for Genomic Research for providing us with A. thaliana spike-in controls and the Plataforma de Transcriptòmica of the Universitat de Barcelona (PCB-SCT-UB) for help with microarray preparation. EB was supported by Juan de la Cierva postdoctoral fellowship, AP by grant BFU05-24129-E, and SB and MRR by a FPI fellowship from the Ministerio de Ciencia e Innovación (MICINN), Spain. This project was funded by grants BMC2006-07334, ACl2009-0903 and Consolider Ingenio 2010 (CSD200700008) from MICINN, Spain. 


\section{Author details}

${ }^{1}$ Serveis Científico-Tècnics de la Universitat de Barcelona (SCT-UB), Barcelona, Catalonia, Spain. ${ }^{2}$ Fibran SA, Sant Joan de les Abadesses, Catalonia, Spain. ${ }^{3}$ Departament de Genètica, and Institut de Biomedicina de la Universitat de Barcelona (IBUB), Diagonal 645, 08028 Barcelona, Catalonia, Spain.

\section{Authors' contributions}

EB performed the bioinformatics analysis; $S B, M B, F S$ and $M C$ conceived and designed the experiments; MRR, SB, MB and AP performed the experiments; FS and MC contributed reagents and materials; EB and $M C$ wrote the paper. All authors read and approved the final manuscript.

Received: 28 June 2010 Accepted: 2 September 2010

Published: 2 September 2010

\section{References}

1. Brockes JP, Kumar A: Comparative aspects of animal regeneration. Annu Rev Cell Dev Biol 2008, 24:525-549.

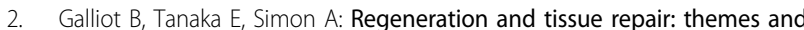
variations. Cell Mol Life Sci 2008, 65:3-7.

3. Morgan TH: Regeneration and Liability to Injury. Science 1901, 14:235-248.

4. Saló E: The power of regeneration and the stem-cell kingdom: freshwater planarians (Platyhelminthes). Bioessays 2006, 28:546-559.

5. Galliot B, Miljkovic-Licina M, de Rosa R, Chera S: Hydra, a niche for cell and developmental plasticity. Semin Cell Dev Biol 2006, 17:492-502.

6. Tseng AS, Levin M: Tail regeneration in Xenopus laevis as a model for understanding tissue repair. J Dent Res 2008, 87:806-816.

7. Yokoyama $\mathrm{H}$ : Initiation of limb regeneration: the critical steps for regenerative capacity. Dev Growth Differ 2008, 50:13-22.

8. Kragl M, Knapp D, Nacu E, Khattak S, Maden M, et al: Cells keep a memory of their tissue origin during axolotl limb regeneration. Nature 2009, 460:60-65.

9. Poss KD: Getting to the heart of regeneration in zebrafish. Semin Cell Dev Biol 2007, 18:36-45.

10. Dor $Y$, Stanger BZ: Regeneration in liver and pancreas: time to cut the umbilical cord? Sci STKE 2007, 66.

11. Zaret KS, Grompe M: Generation and regeneration of cells of the liver and pancreas. Science 2008, 322:1490-1494.

12. Lien $\mathrm{CL}$, Schebesta M, Makino S, Weber GJ, Keating MT: Gene expression analysis of zebrafish heart regeneration. PLoS Biol 2006, 4:e260.

13. Marsh JL, Theisen H: Regeneration in insects. Semin Cell Dev Biol 1999, 10:365-375.

14. Bergantinos C, Vilana X, Corominas M, Serras F: Imaginal discs: Renaissance of a model for regenerative biology. Bioessays 2010, 32:207-217.

15. Hadorn E: Transdetermination in cells. Sci Am 1968, 219:110-114, passim.

16. Maves L, Schubiger G: Transdetermination in Drosophila imaginal discs: a model for understanding pluripotency and selector gene maintenance. Curr Opin Genet Dev 2003, 13:472-479.

17. Bosch M, Serras F, Martin-Blanco E, Baguna J: JNK signaling pathway required for wound healing in regenerating Drosophila wing imaginal discs. Dev Biol 2005, 280:73-86.

18. Mattila J, Omelyanchuk L, Kyttala S, Turunen H, Nokkala S: Role of Jun Nterminal Kinase (JNK) signaling in the wound healing and regeneration of a Drosophila melanogaster wing imaginal disc. Int J Dev Biol 2005, 49:391-399.

19. Bosch M, Baguna J, Serras F: Origin and proliferation of blastema cells during regeneration of Drosophila wing imaginal discs. Int J Dev Biol 2008, 52:1043-1050.

20. McClure $K D$, Schubiger $G$ : A screen for genes that function in leg disc regeneration in Drosophila melanogaster. Mech Dev 2008, 125:67-80.

21. Martin P, Parkhurst SM: Parallels between tissue repair and embryo morphogenesis. Development 2004, 131:3021-3034.

22. Ip YT, Davis RJ: Signal transduction by the c-Jun N-terminal kinase (JNK)from inflammation to development. Curr Opin Cell Biol 1998, 10:205-219.

23. Zeitlinger J, Bohmann D: Thorax closure in Drosophila: involvement of Fos and the JNK pathway. Development 1999, 126:3947-3956.

24. Martin-Blanco E, Gampel A, Ring J, Virdee K, Kirov N, et al: puckered encodes a phosphatase that mediates a feedback loop regulating JNK activity during dorsal closure in Drosophila. Genes Dev 1998, 12:557-570.
25. Lee N, Maurange C, Ringrose L, Paro R: Suppression of Polycomb group proteins by JNK signalling induces transdetermination in Drosophila imaginal discs. Nature 2005, 438:234-237.

26. Bergantinos C, Corominas M, Serras F: Cell death-induced regeneration in wing imaginal discs requires JNK signalling. Development 2010, 137:1169-1179.

27. Clevers $\mathrm{H}$ : Wnt/beta-catenin signaling in development and disease. Cell 2006, 127:469-480.

28. Smith-Bolton RK, Worley MI, Kanda H, Hariharan IK: Regenerative growth in Drosophila imaginal discs is regulated by Wingless and Myc. Dev Cell 2009, 16:797-809.

29. Stoick-Cooper CL, Weidinger G, Riehle KJ, Hubbert C, Major MB, et al: Distinct Wnt signaling pathways have opposing roles in appendage regeneration. Development 2007, 134:479-489.

30. Maves $L$, Schubiger $G$ : Wingless induces transdetermination in developing Drosophila imaginal discs. Development 1995, 121:1263-1272.

31. Klebes A, Sustar A, Kechris K, Li H, Schubiger G, et al: Regulation of cellular plasticity in Drosophila imaginal disc cells by the Polycomb group, trithorax group and lama genes. Development 2005, 132:3753-3765.

32. Bray SJ: Notch signalling: a simple pathway becomes complex. Nat Rev Mol Cell Biol 2006, 7:678-689.

33. Raya A, Koth CM, Buscher D, Kawakami Y, Itoh T, et al: Activation of Notch signaling pathway precedes heart regeneration in zebrafish. Proc Natl Acad Sci USA 2003, 100(Suppl 1):11889-11895.

34. Conboy IM, Conboy MJ, Smythe GM, Rando TA: Notch-mediated restoration of regenerative potential to aged muscle. Science 2003, 302:1575-1577.

35. Mattila J, Omelyanchuk L, Nokkala S: Dynamics of decapentaplegic expression during regeneration of the Drosophila melanogaster wing imaginal disc. Int J Dev Biol 2004, 48:343-347.

36. Reddien PW, Bermange AL, Murfitt KJ, Jennings JR, Sanchez Alvarado A: Identification of genes needed for regeneration, stem cell function, and tissue homeostasis by systematic gene perturbation in planaria. Dev Cell 2005, 8:635-649.

37. Grow M, Neff AW, Mescher AL, King MW: Global analysis of gene expression in Xenopus hindlimbs during stage-dependent complete and incomplete regeneration. Dev Dyn 2006, 235:2667-2685.

38. Pruitt KD, Tatusova T, Maglott DR: NCBI reference sequences (RefSeq): a curated non-redundant sequence database of genomes, transcripts and proteins. Nucleic Acids Res 2007, 35:D61-65.

39. Ashburner M, Ball CA, Blake JA, Botstein D, Butler H, et al: Gene ontology: tool for the unification of biology. The Gene Ontology Consortium. Nat Genet 2000, 25:25-29.

40. Stramer B, Winfield M, Shaw T, Millard TH, Woolner S, et al: Gene induction following wounding of wild-type versus macrophage-deficient Drosophila embryos. EMBO Rep 2008, 9:465-471.

41. Subramanian A, Tamayo P, Mootha VK, Mukherjee S, Ebert BL, et al: Gene set enrichment analysis: a knowledge-based approach for interpreting genome-wide expression profiles. Proc Natl Acad Sci USA 2005, 102:15545-15550.

42. Dichtel-Danjoy ML, Caldeira J, Casares F: SoxF is part of a novel negativefeedback loop in the wingless pathway that controls proliferation in the Drosophila wing disc. Development 2009, 136:761-769.

43. Lee HJ, Goring W, Ochs M, Muhlfeld C, Steding G, et al: Sox15 is required for skeletal muscle regeneration. Mol Cell Biol 2004, 24:8428-8436.

44. Affolter $M$, Basler K: The Decapentaplegic morphogen gradient: from pattern formation to growth regulation. Nat Rev Genet 2007, 8:663-674

45. Kal AJ, Mahmoudi T, Zak NB, Verrijzer CP: The Drosophila brahma complex is an essential coactivator for the trithorax group protein zeste. Genes Dev 2000, 14:1058-1071.

46. Ito T, Bulger M, Kobayashi R, Kadonaga JT: Drosophila NAP-1 is a core histone chaperone that functions in ATP-facilitated assembly of regularly spaced nucleosomal arrays. Mol Cell Biol 1996, 16:3112-3124.

47. Munoz-Descalzo S, Terol J, Paricio N: Cabut, a $\mathrm{C} 2 \mathrm{H} 2$ zinc finger transcription factor, is required during Drosophila dorsal closure downstream of JNK signaling. Dev Biol 2005, 287:168-179.

48. Munoz-Descalzo S, Belacortu Y, Paricio N: Identification and analysis of cabut orthologs in invertebrates and vertebrates. Dev Genes Evol 2007 217:289-298. 
49. Peretz G, Bakhrat A, Abdu U: Expression of the Drosophila melanogaster GADD45 homolog (CG11086) affects egg asymmetric development that is mediated by the c-Jun N-terminal kinase pathway. Genetics 2007, 177:1691-1702.

50. Hewes RS, Schaefer AM, Taghert PH: The cryptocephal gene (ATF4) encodes multiple basic-leucine zipper proteins controlling molting and metamorphosis in Drosophila. Genetics 2000, 155:1711-1723.

51. Wang MC, Bohmann D, Jasper H: JNK extends life span and limits growth by antagonizing cellular and organism-wide responses to insulin signaling. Cell 2005, 121:115-125.

52. Clark AG, Eisen MB, Smith DR, Bergman CM, Oliver B, et al: Evolution of genes and genomes on the Drosophila phylogeny. Nature 2007, 450:203-218.

53. Jochum W, Passegue E, Wagner EF: AP-1 in mouse development and tumorigenesis. Oncogene 2001, 20:2401-2412.

54. Eferl R, Wagner EF: AP-1: a double-edged sword in tumorigenesis. Nat Rev Cancer 2003, 3:859-868.

55. Jennings $\mathrm{BH}$, Tyler DM, Bray SJ: Target specificities of Drosophila enhancer of split basic helix-loop-helix proteins. Mol Cell Biol 1999, 19:4600-4610.

56. Jones S: An overview of the basic helix-loop-helix proteins. Genome Biol 2004, 5:226.

57. Orian A, van Steensel B, Delrow J, Bussemaker HJ, Li L, et al: Genomic binding by the Drosophila Myc, Max, Mad/Mnt transcription factor network. Genes Dev 2003, 17:1101-1114.

58. Beltran S, Blanco E, Serras F, Perez-Villamil B, Guigo R, et al: Transcriptional network controlled by the trithorax-group gene ash2 in Drosophila melanogaster. Proc Natl Acad Sci USA 2003, 100:3293-3298.

59. Shilatifard A: Molecular implementation and physiological roles for histone H3 lysine 4 (H3K4) methylation. Curr Opin Cell Biol 2008, 20:341-348.

60. Papoulas O, Daubresse G, Armstrong JA, Jin J, Scott MP, et al: The HMGdomain protein BAP111 is important for the function of the BRM chromatin-remodeling complex in vivo. Proc Natl Acad Sci USA 2001, 98:5728-5733.

61. Moller A, Avila FW, Erickson JW, Jackle H: Drosophila BAP60 is an essential component of the Brahma complex, required for gene activation and repression. J Mol Biol 2005, 352:329-337.

62. Noselli S, Agnes F: Roles of the JNK signaling pathway in Drosophila morphogenesis. Curr Opin Genet Dev 1999, 9:466-472.

63. Pearson JC, Juarez MT, Kim M, Drivenes O, McGinnis W: Multiple transcription factor codes activate epidermal wound-response genes in Drosophila. Proc Natl Acad Sci USA 2009, 106:2224-2229.

64. Herranz H, Milan M: Signalling molecules, growth regulators and cell cycle control in Drosophila. Cell Cycle 2008, 7:3335-3337.

65. Biteau B, Hochmuth CE, Jasper H: JNK activity in somatic stem cells causes loss of tissue homeostasis in the aging Drosophila gut. Cell Stem Cell 2008, 3:442-455

66. Gurtner GC, Werner S, Barrandon Y, Longaker MT: Wound repair and regeneration. Nature 2008, 453:314-321.

67. Stoick-Cooper CL, Moon RT, Weidinger G: Advances in signaling in vertebrate regeneration as a prelude to regenerative medicine. Genes Dev 2007, 21:1292-1315.

68. Ryder E, Ashburner M, Bautista-Llacer R, Drummond J, Webster J, et al: The DrosDel deletion collection: a Drosophila genomewide chromosomal deficiency resource. Genetics 2007, 177:615-629.

69. Beltran S, Angulo M, Pignatelli M, Serras F, Corominas M: Functional dissection of the ash2 and ash1 transcriptomes provides insights into the transcriptional basis of wing phenotypes and reveals conserved protein interactions. Genome Biol 2007, 8:R67.

70. Sturtevant MA, Biehs B, Marin E, Bier E: The spalt gene links the A/P compartment boundary to a linear adult structure in the Drosophila wing. Development 1997, 124:21-32.

71. Vandesompele J, De Preter K, Pattyn F, Poppe B, Van Roy N, et al: Accurate normalization of real-time quantitative RT-PCR data by geometric averaging of multiple internal control genes. Genome Biol 2002, 3: RESEARCH0034.

72. Blanco E, Pignatelli M, Beltran S, Punset A, Perez-Lluch S, et al: Conserved chromosomal clustering of genes governed by chromatin regulators in Drosophila. Genome Biol 2008, 9:R134.
73. Smyth GK: Linear models and empirical bayes methods for assessing differential expression in microarray experiments. Stat Appl Genet Mol Biol 2004, 3:Article 3.

74. Gentleman RC, Carey VJ, Bates DM, Bolstad B, Dettling M, et al: Bioconductor: open software development for computational biology and bioinformatics. Genome Biol 2004, 5:R80.

75. Edgar R, Domrachev M, Lash AE: Gene Expression Omnibus: NCBI gene expression and hybridization array data repository. Nucleic Acids Res 2002 30:207-210.

76. Kuhn RM, Karolchik D, Zweig AS, Trumbower H, Thomas DJ, et al: The UCSC genome browser database: update 2007. Nucleic Acids Res 2007, 35 D668-673.

77. The Gene Ontology Consortium: The Gene Ontology project in 2008. Nucleic Acids Res 2008, 36:D440-444.

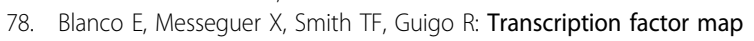
alignment of promoter regions. PLoS Comput Biol 2006, 2:e49.

\section{doi:10.1186/1471-213X-10-94}

Cite this article as: Blanco et al:: Gene expression following induction of regeneration in Drosophila wing imaginal discs. Expression profile of regenerating wing discs. BMC Developmental Biology 2010 10:94.

\section{Submit your next manuscript to BioMed Central and take full advantage of:}

- Convenient online submission

- Thorough peer review

- No space constraints or color figure charges

- Immediate publication on acceptance

- Inclusion in PubMed, CAS, Scopus and Google Scholar

- Research which is freely available for redistribution

Submit your manuscript at www.biomedcentral.com/submit
C) Biomed Central 